\title{
COVID-19 and Vaccination in the Setting of Neurologic Disease
}

\section{An Emerging Issue in Neurology}

Elisabeth B. Marsh, MD, Michael Kornberg, MD, PhD, Kevin Kessler, MD, Ihtsham Haq, MD, Anup D. Patel, MD, Avindra Nath, MD, Becky Schierman, MPH, and Lyell K. Jones, Jr., MD, on behalf of the Quality Committee of the American Academy of Neurology

Neurology ${ }^{\circledR} 2021 ; 97: 720-728$. doi:10.1212/WNL.0000000000012578

\section{Abstract}

The coronavirus disease 2019 (COVID-19) pandemic caused by the severe acute respiratory syndrome coronavirus 2 (SARS-CoV-2) has left many unanswered questions for patients with neurologic disorders and the providers caring for them. Elderly and immunocompromised patients are at increased risk for severe symptoms due to COVID-19, and the virus may increase symptoms of underlying neurologic illness, particularly for those with substantial bulbar and respiratory weakness or other neurologic disability. Emerging SARS-CoV-2 vaccines offer substantial protection from symptomatic infection, but both patients and providers may have concerns regarding theoretical risks of vaccination, including vaccine safety and efficacy in the context of immunotherapy and the potential for precipitating or exacerbating neurologic symptoms. In this statement on behalf of the Quality Committee of the American Academy of Neurology, we review the current literature, focusing on COVID-19 infection in adults with neurologic disease, in order to elucidate risks and benefits of vaccination in these individuals. Based on existing evidence, neurologists should recommend COVID-19 vaccination to their patients. For those patients being treated with immunotherapies, attention should be paid to timing of vaccination with respect to treatment and the potential for an attenuated immune response.

\author{
Correspondence \\ Dr. Marsh \\ ebmarsh@jhmi.edu
}

\section{MORE ONLINE}

COVID-19 Resources

For the latest articles, invited commentaries, and blogs from physicians around the world NPub.org/COVID19

From The Johns Hopkins School of Medicine (E.B.M., M.K.), Baltimore, MD; The University of Virginia Medical Center (K.K.), Charlottesville; The University of Miami Miller School of Medicine (I.H.), FL; Nationwide Children's Hospital (A.D.P.), Columbus, OH; The National Institutes of Health (A.N.), Bethesda, MD; The American Academy of Neurology (B.S.), Minneapolis; and The Mayo Clinic (L.K.J.), Rochester, MN.

Go to Neurology.org/N for full disclosures. Funding information and disclosures deemed relevant by the authors, if any, are provided at the end of the article.

This article was reviewed and approved for publication by the Quality Committee and board members of the American Academy of Neurology on March $12,2021$.

The Article Processing Charge was funded by the authors.

This is an open access article distributed under the terms of the Creative Commons Attribution-NonCommercial-NoDerivatives License 4.0 (CC BY-NC-ND), which permits downloading and sharing the work provided it is properly cited. The work cannot be changed in any way or used commercially without permission from the journal. 


\section{Glossary}

ADEM = acute disseminated encephalomyelitis; AIDP = acute inflammatory demyelinating polyneuropathy; CIDP = chronic inflammatory demyelinating polyneuropathy; COVID-19 = coronavirus disease 2019; FDA = US Food and Drug Administration; mRNA = messenger RNA; MS = multiple sclerosis; PEP = postencephalitic parkinsonism; $\mathbf{q R T}$-PCR = quantitative real-time polymerase chain reaction; SARS-CoV-2 = severe acute respiratory syndrome coronavirus 2; VAERS = Vaccine Adverse Events Reporting System.

The coronavirus disease 2019 (COVID-19) pandemic caused by the novel severe acute respiratory syndrome coronavirus 2 (SARS-CoV-2) has resulted in over 3 million deaths worldwide ${ }^{1}$ and nearly 600,000 in the United States alone. High rates of infection and subsequent long-term sequelae have raised significant concerns, particularly for those with underlying medical illnesses, who may be more severely affected. This includes not only those treated with immunosuppressive therapies for their neurologic disorders (e.g., myasthenia gravis or multiple sclerosis [MS]) but also those with significant functional disability from their disease and elderly patients with a history of cerebrovascular disease and dementia. As neurologic disorders are common, ${ }^{2}$ the effect of SARS-CoV-2 on patients with neurologic illnesses poses a substantial public health risk. Consideration of this population is critical when considering the risks and benefits of vaccination.

The approval of 3 vaccines (PfizerBioNTech, Moderna, and Johnson \& Johnson) by the US Food and Drug Administration (FDA) for emergency use results in the potential to significantly reduce the incidence of symptomatic disease in these vulnerable populations. ${ }^{3-5}$ However, the rapidity of approval, and history of prior vaccination regimens resulting in neurologic and other complications, ${ }^{6}$ creates concern surrounding widespread vaccination. This is particularly so in groups with preexisting neurologic conditions. In this statement, written on behalf of the Quality Committee and approved by the Board of Directors of the American Academy of Neurology, we review the risk of COVID-19 in adults with neurologic disorders. We also review the potential risks associated with vaccination using data from the existing COVID-19 vaccination trials and known history of responses to vaccines for other diseases. Finally, we provide guidance on the optimal timing of vaccination for those on immunotherapies and recommendations for groups with specific neurologic disorders. This additional information will allow medical providers to better guide their patient populations toward safe and effective prevention strategies, lowering the overall rate of COVID-19 transmission, decreasing disease severity, and optimizing neurologic health. This article reflects the impressions of the authors based on currently available data.

\section{Effect of COVID-19 on Patients With Neurologic Disorders}

With its wide range of disease severity ranging from asymptomatic carriers to severe respiratory compromise and death,
SARS-CoV-2 has affected more than 110 million individuals worldwide. ${ }^{1}$ The potential for neurologic complications is concerning, particularly for those who already have neurologic disorders. Neurologic complications have been reported in $30 \%-60 \%$ of patients with COVID-19 and typically fall into 3 broad categories: those that are caused acutely by the virus' systemic effects on the body itself, those that result from direct invasion of the nervous system, and those with long-term sequelae after an individual has recovered from the acute illness. Although there is no clear evidence at this time that those with preexisting neurologic illness are at higher risk of infection or neurologic complications, the question of whether individuals with neuromuscular or bulbar weakness may be more vulnerable to either infection or neurologic sequelae will require careful study.

Prevalence data on acute neurologic effects of COVID-19 are limited. In an article published in JAMA Neurology detailing 214 COVID-19-positive patients hospitalized in Wuhan, China, headache and dizziness were the most commonly reported neurologic complaints and seen early after symptom onset. $^{7}$ These early symptoms contrast with the encephalopathy seen days to weeks into the hospital course of patients with severe disease. Encephalitis has been reported, mainly in a series of case reports, ${ }^{8,9}$ although imaging and CSF profiles have been nonspecifically abnormal or nonrevealing. ${ }^{10}$

Evidence is largely lacking for direct CNS invasion of SARS$\mathrm{CoV}-2$ as a primary cause of neurologic sequelae. Several studies have detected low viral loads in brain tissue using quantitative real-time polymerase chain reaction (qRTPCR),${ }^{1-14}$ but the clinical significance of these findings is uncertain. For instance, a recent autopsy study of 41 consecutive patients who died of SARS-CoV-2 infection found low to very low viral RNA levels in some of the brains by qRTPCR, but viral proteins were not detected, and the level of detectable RNA did not correlate with histopathologic alterations. ${ }^{14}$ Other studies have not been able to detect viral RNA or protein in the brain. ${ }^{11,15}$ Based on rodent studies with other coronaviruses, researchers have speculated that the virus might be able to enter the CNS via retrograde dissemination. Thus far, evidence for SARS-CoV-2 doing so is lacking. ${ }^{16}$ The virus does infect the sustenacular cells of the nasal mucosa, causing inflammation that causes loss of smell and headache. ${ }^{17,18}$ Similar systemic inflammatory effects of the virus might cause altered mental status in patients either directly or through an inflammatory cascade leading to cardiac 
or respiratory compromise with hypoxia or thrombosis. ${ }^{7,10,19}$ CNS effects have also been hypothesized to be caused by damage to vascular endothelium or blood-brain barrier breakdown. ${ }^{19}$ There have been case reports suggesting increased risk of large vessel occlusion and ischemic stroke associated with infection in the young. ${ }^{20}$ It is also possible that the virus triggers underlying neurologic disease through immunomodulation as there have been case reports of acute inflammatory demyelinating polyneuropathy (AIDP), acute myoclonus, acute cerebellitis with ataxia, encephalitis, and status epilepticus occurring as para- or postinfectious phenomena. $9,21-24$

Long-term sequelae have been reported following previous viral epidemics; however, clear evidence linking specific complications to prior viral infection remains somewhat controversial and does not appear related to a single mechanism of action. The $1918 \mathrm{H} 1 \mathrm{~N} 1$ pandemic's association with postencephalitic parkinsonism (PEP) and Zika virus-induced congenital Zika syndrome are prominent examples. PEP is associated with encephalitis lethargica (von Economo encephalitis). Although encephalitis lethargica has been associated with the H1N1 epidemic, this association has been challenged. $^{25}$ Moreover, the idea that PEP had a one-to-one relationship with encephalitis lethargica has also come into question. $^{26}$ Unlike the putative postinfectious autoimmune etiology of PEP, Zika syndrome is in large part the direct result of acute infectious injury to developing brain. ${ }^{27}$ Any report of long-term neurologic sequelae of COVID-19 will require careful epidemiologic and mechanistic analysis to demonstrate the validity of the association. That said, reports of long-term neurologic sequelae after recovery from COVID19 have begun to accrue, and thus far include dysautonomia, chronic fatigue, and cognitive impairment. ${ }^{28}$ More time is needed to fully characterize these issues and estimate their incidence. Global registries will be crucial for determining whether SARS-CoV-2 infection, like other viral infections, will be associated with increased incidence of psychiatric disease, dementia, thrombosis, or demyelination later in life. True causality can be difficult to establish, so associations with neurologic syndromes are typically labeled as "probable" or "possible." 8 No definitive pathophysiologic mechanism has yet been established for acute or chronic neurologic symptoms following COVID-19.

Some literature supports the indirect effect of viral infections on those with neurologic disorders. ${ }^{8}$ Along with potentially triggering disease, there is an increased risk of mortality in patients with preexisting neuromuscular illness who contracted influenza or pneumococcal pneumonia due to worsening respiratory status. ${ }^{29,30}$ Exacerbations of symptoms are commonly associated with infections, with infection accounting for almost half of patients presenting with myasthenia gravis flares. ${ }^{31}$ Viral infections are a common cause of pseudorelapse (transient worsening of existing symptoms) in people with MS, and increased disability has been identified as a risk factor for severe COVID-19 in patients with MS. ${ }^{32,33}$
Viral illnesses can be a predisposing factor for delirium in patients with dementia or mild cognitive impairment, leading to poor prognosis. In addition, those on immunomodulating therapy are at risk for more severe, recurrent, and persistent infection. ${ }^{34}$ In patients with MS, anti-CD20 therapies have been linked with a more severe course of COVID-19. ${ }^{33}$

In conjunction with its effect on patient health, COVID-19 has had profound effects on our health care system. The pandemic has been linked to decreased hospitalizations for those with ischemic stroke and other neurologic illnesses, ${ }^{35}$ resulting in poor access to care and the potential future increased burden of undiagnosed and untreated ischemic disease. Vaccination against SARS-CoV-2 infection may inspire confidence and allow the anxious to seek the care required to prevent increased morbidity and mortality.

\section{COVID-19 Vaccines Currently Approved for Use in the United States}

\section{Mechanisms of Action}

To lower overall viral transmission through herd immunity and decrease disease severity, particularly in vulnerable populations, 3 vaccines using distinct approaches have been approved by the FDA for emergency use. None of these vaccines utilizes inactivated or live-attenuated SARS-CoV-2 virus, nor do they use recombinant protein technology (the 3 most commonly used technologies for vaccine development in the past). Two of these (Pfizer and Moderna) utilize a novel messenger RNA (mRNA) approach, in which mRNA encoding a subunit of the SARS-CoV-2 spike protein is encapsulated within lipid nanoparticles to increase stability and augment uptake by antigen presenting cells. ${ }^{36}$ After uptake, the mRNA is translated into antigenic spike protein, inducing cell-based and humoral immune responses. This technology has advantages with regard to vaccine production and potentially immunogenicity and has been shown to be effective in animal models and clinical trials against a wide variety of infectious agents. ${ }^{37}$ Under emergency use authorization, it is now being used to vaccinate against SARS-CoV-2. The Johnson \& Johnson vaccine, in contrast, utilizes a replicationdeficient adenovirus vector to deliver DNA encoding the SARS-CoV-2 spike protein into host cells, which is then transcribed/translated into antigenic protein. Adenoviruses are common cold-causing viruses. ${ }^{36}$ In the context of the Johnson \& Johnson vaccine, the adenovirus has been genetically engineered to prevent replication, meaning it cannot produce an active adenovirus infection. A similar platform has been used in a prior Ebola virus vaccine approved for use in the European Union. ${ }^{38}$ Because none of the currently approved vaccines utilize live-attenuated SARS-CoV-2 virus, none has the potential to cause SARS-CoV-2 infection.

\section{Safety and Efficacy}

mRNA-based vaccine approaches provide a novel, highly potent mechanism toward building immunity. ${ }^{37}$ In a multinational 
randomized placebo-controlled trial of $>40,000$ people, the Pfizer vaccine was found to be $95 \%$ effective against development of symptomatic disease in recipients compared to controls. ${ }^{4}$ In their initial report to the FDA, fatigue and headache were the most frequent side effects of vaccination and initial severe systemic symptoms occurred in only about $2 \%$ of participants. Longer term severe events were rare, occurring in only 4 participants, and included shoulder injury, lymphadenopathy, ventricular arrythmia, and paresthesias. Similar results were seen with the Moderna vaccine. ${ }^{3}$

The most recent safety data are provided in the preliminary analysis of a multicenter phase 3 trial of $>30,000$ volunteers assigned to mRNA-1273 SARS-CoV-2 vaccine (Moderna) vs placebo. The trial showed high efficacy (94.1\%) and a low rate of complications in individuals at high risk for infection and mortality due to COVID-19 who received active vaccine. ${ }^{39}$ Whereas neurologic illness was not an inclusion criterion, other high-risk comorbidities such as heart failure, pulmonary hypertension, diabetes, and HIV infection resulted in a diverse population with multiple comorbidities that would be expected to encompass some patients with neurologic disease. The most frequent complications included injection site reactions, headache, and fatigue. Severe adverse events attributable to vaccine or placebo were uncommon, and similar between the vaccine and placebo groups ( $0.5 \%$ vs $0.2 \%)$.

The Johnson \& Johnson vaccine phase 3 trial differed from the Moderna and Pfizer trials in its prespecified outcomes, timing, and setting. It found a $66 \%$ reduction in moderate to severe COVID-19 in its treatment arm, with $85 \%$ reduction in severe disease and no hospitalizations or COVID-19-related deaths compared to controls. Recently, blood clots occurring 7-14 days after administration have been reported, primarily in young women on oral contraceptive medications, though whether this is higher than the baseline rate of thrombosis in this group and whether the mechanism can be reliably linked to vaccine administration is under investigation. In these events, vaccination was typically followed by cerebral venous sinus thrombosis, which was associated with thrombocytopenia and antibodies to platelet activating factor- $4 .{ }^{40,41}$ In April 2021, the FDA instituted a 10-day pause in the use of the Johnson \& Johnson vaccine for further evaluation of these events, which constituted 6 cases out of approximately 7.98 million doses given. Following review, the recommendation and emergency use authorization for this vaccine were reaffirmed for individuals aged 18 years and older, with a warning regarding rare clotting events primarily among women aged $18-49$ years. ${ }^{42}$ Of note, similar rare clotting events that appear to share a pathophysiologic mechanism have been reported with the Oxford/AstraZeneca vaccine approved outside the United States, with an estimated incidence of 1 in $40,000 .{ }^{43}$ This vaccine uses a similar adenovirus-based mechanism.

Although neurologic side effects were not more commonly observed following active vaccine over the extended follow-up period for any of the vaccines, a number of neurologic complications of these vaccines are now being reported in the most comprehensive registry, the Vaccine Adverse Events Reporting System (VAERS) database. These include strokes, cranial neuropathies including Bell palsy, tinnitus and trigeminal neuralgia, peripheral neuropathies, dysautonomia, acute disseminated encephalomyelitis, transverse myelitis, and AIDP. ${ }^{44}$ Case reports are also starting to emerge in the published literature ${ }^{45,46}$ and the popular press. Most recently, the possibility of increased risk of AIDP in the weeks following vaccination was formally added to the label for the Johnson \& Johnson vaccine. These complications are rare when compared to the large number of vaccinated individuals; however, it is too early to know the true incidence and risk factors for these complications. They are thought to be immune-mediated and early recognition and treatment with immunomodulatory therapies might be warranted. There are little to no data regarding the safety or efficacy of the COVID19 vaccines in patients with preexisting neurologic conditions or patients receiving immunomodulatory therapies. Based on COVID-19 vaccine data from the general population and extrapolations from other vaccines studied in patients with neurologic disease, statements from the American Academy of Neuromuscular and Electrodiagnostic Medicine and the National Multiple Sclerosis Society support vaccination. ${ }^{47,48}$ As discussed further below, a single study has now reported no increased risk of complications in patients with MS receiving the Pfizer COVID-19 vaccine. ${ }^{49}$

\section{Additional Considerations From Prior Vaccine Experience}

With regard to vaccination in patients with neurologic disease, several concerns arise. First, what is the risk a particular vaccine might precipitate or worsen neurologic disease? Although this concern applies to all neurologic patients, it may be most relevant to those with preexisting inflammatory/ autoimmune neurologic conditions. Second, given that patients with neurologic diseases are increasingly treated with therapies that either modulate or suppress the immune system, concerns arise regarding the risk that a vaccine might produce active infection and whether vaccine efficacy might be reduced in the context of these therapies.

As discussed above, none of the currently approved COVID19 vaccines utilize live-attenuated SARS-CoV-2 and thus none has the potential to produce SARS-CoV-2 infection. The Johnson \& Johnson vaccine (along with vaccines using similar technology available outside the United States) utilizes an adenovirus vector to deliver nucleic acids encoding the SARS-CoV-2 spike protein but the adenovirus has been genetically engineered to prevent replication. It cannot produce adenovirus infection even in immunocompromised individuals. Beyond this concern, much of our knowledge about the safety and efficacy of vaccination in neurologic patients comes from the results of previous vaccine studies and our understanding of the mechanisms of action of commonly used 
immunotherapies. It must be noted, of course, that the currently available COVID-19 vaccines utilize largely novel technologies, complicating precise extrapolations from prior experience.

\section{Neurologic Complications Associated With Prior Vaccines}

Prior studies have shed light on the likelihood of neurologic complications following vaccination. These data can be difficult to interpret and are often seen as controversial, suffering from potential reporting bias and lack of clear causality, but illustrate theoretical concerns for both patients and physicians and must be acknowledged. The VAERS Database has reported adverse events affecting both the central and peripheral nervous systems, although clear causal relationships remain difficult to establish. AIDP is the most common neurologic syndrome and has been described in case reports following vaccination for influenza, polio, rabies, meningococcus, measles, mumps, and tetanus. ${ }^{50}$ Vaccination for H1N1 in 1976 was associated with an increased risk of AIDP of 1 additional case per 100,000 vaccinated individuals. ${ }^{51}$ These cases occurred between 1 and 6 weeks following immunization. On this basis, the vaccine was discontinued in January 1977. However, one must also consider the baseline rate of Guillain-Barré and seasonal variability when interpreting these data. The 2009 H1N1 epidemic showed that individuals were actually more likely to experience AIDP after viral infection than after administration of the vaccine, ${ }^{52}$ and subsequent influenza vaccines have been considered safe with an excess risk of about 0.1 case per 100,000 vaccinations. $^{53-59}$ Case reports of AIDP have been reported with a number of vaccines such as hepatitis A, Japanese encephalitis, smallpox, yellow fever, and meningococcus. ${ }^{60}$ Current guidelines by the advisory committee on immunization practices of the Centers for Disease Control \& Prevention list AIDP within 6 weeks of previous influenza as a precaution for immunization against influenza. This means that while the risks may be elevated, individual risks vs benefits should be considered before recommending immunization. ${ }^{\text {el }}$ Vaccination has been associated with the development of chronic inflammatory demyelinating polyneuropathy (CIDP) in $1.5 \%$ of patients with CIDP within 6 weeks of administration $^{\mathrm{e} 2}$ and worsening symptoms were also reported after tetanus vaccination in $8.7 \%$ of patients. ${ }^{\text {e3 }}$ The overall rate of complications is rare and consideration of vaccination type is also important when considering risk.

In addition to peripheral nervous system effects, CNS involvement has been reported most often in the form of acute disseminated encephalomyelitis (ADEM). In the early 1990s, seizures and encephalitis were loosely linked to the diphtheriatetanus-pertussis vaccine, ${ }^{\mathrm{e}}$ although later studies reported no increased seizure frequency over baseline. ${ }^{\text {es }}$ ADEM has been reported in the form of case reports with the antirabies vaccine, ${ }^{\text {e6-e8 }}$ as well as vaccinations to yellow fever, Japanese encephalitis, measles, influenza, smallpox, anthrax, and others. The strongest association of ADEM has been with the Semple rabies vaccine, likely because it was made in cells derived from the nervous system. ${ }^{60}$ With regard to MS, theoretical concerns about vaccines precipitating relapses have existed for decades, ${ }^{\text {e6 }}$ although published studies have failed to identify any correlation between vaccination and either initial or subsequent clinical attacks. $^{\text {e7-e10 }}$ In contrast, several vaccines have been possibly linked to a lower risk of subsequent MS diagnosis. ${ }^{\text {e8 }}$ Thus far, a single study of adult patients with MS receiving the Pfizer COVID-19 vaccine (555 having received the first dose and 435 having received the second dose) demonstrated no safety concerns and no increased risk of relapse. ${ }^{49}$

\section{Vaccine Efficacy in Patients Receiving Immunotherapies}

Studies of COVID-19 vaccine efficacy in patients receiving immunotherapies are limited. A recently published real-world study of the Pfizer COVID-19 vaccine found that 2 doses of the vaccine reduced SARS-CoV-2 infection by $71 \%$ in immunosuppressed patients compared to a $90 \%$ reduction among the nonimmunosuppressed. ${ }^{\text {e11 }}$ However, the specific therapies used and the definition of immunosuppression were not reported. A small study of patients with rheumatic and musculoskeletal diseases found a blunted antibody response to 2 doses of SARS-CoV-2 mRNA vaccine in those treated with glucocorticoids ( $82 \%$ seroconversion), mycophenolate ( $73 \%$ seroconversion), or rituximab ( $26 \%$ seroconversion). ${ }^{\text {e12 }}$

Despite limited data specific to COVID-19 vaccination, prior studies have been helpful in elucidating the effect of immunomodulatory and immunosuppressive therapies on vaccine response. In general, immunomodulatory therapies have less effect on vaccine response than immunosuppressive or cell-depleting therapies. For patients with MS, there appears to be preserved immunity postvaccination for those taking interferons. ${ }^{\text {e6e } 8} \mathrm{Di}$ methyl fumarate was similarly found to have no effect on vaccine response, although only in a single study. ${ }^{\mathrm{e} 13}$ Glatiramer acetate, teriflunomide, and natalizumab have demonstrated mixed results, with mildly attenuated immune responses in some but not all studies. ${ }^{\text {e14-e20 }}$ Based on mechanism of action and the at most modest effect on vaccine response in prior studies, the above therapies are not expected to substantially decrease the efficacy of COVID-19 vaccines. In contrast, fingolimod, antiCD20 therapies, and alemtuzumab have been shown to significantly impair vaccine responses in prior studies. ${ }^{\text {e21-e23 }}$ A recent study in 23 patients showed that patients treated with cladribine had normal immune responses to the vaccine. ${ }^{\text {24 }}$ For these therapies, timing considerations must be taken into account for vaccination, as outlined in recently released guidelines from the National Multiple Sclerosis Society (Table). ${ }^{\mathrm{e} 25}$ However, it is important to note that partial immunity might still be achieved even with those therapies that blunt measured vaccine responses. Furthermore, many studies of vaccine response have evaluated only humoral (antibody-mediated) immunity, without consideration of cell-mediated T-lymphocyte responses.

In addition to the above MS therapies, other immunotherapies are commonly used in patients with inflammatory/ 
Table Recommendations for Timing of Vaccine Administration for Patients on Common Immunotherapies

\begin{tabular}{l} 
Medications/disease-modifying therapies \\
\hline Multiple sclerosis disease-modifying therapies ${ }^{a}$ \\
\hline Avonex (interferon- $\beta-1 a)$, Betaseron (interferon- $\beta-1 b)$, Copaxone \\
(glatiramer acetate), Extavia (interferon- $\beta-1 b)$, Plegridy \\
(peginterferon- $\beta-1 a)$, Rebif (interferon- $\beta-1 a)$, Aubagio \\
(teriflunomide), Bafiertam (monomethyl fumarate), dimethyl \\
fumarate, Tysabri (natalizumab), Vumerity (diroximel fumarate)
\end{tabular}

Gilenya (fingolimod), Mayzent (siponimod), Zeposia (ozanimod)
Timing of vaccine administration

If starting: Do not delay starting treatment while waiting for the vaccine. If already taking: No adjustments needed. Continue as prescribed.
Lemtrada (alemtuzumab), Mavenclad (cladribine)
If starting: Time dosing so that the second vaccine injection is administered 4 weeks or more before starting medication.

If already taking: No adjustments needed. Continue as prescribed. Vaccine response may be attenuated.

If starting: Time dosing so that the second vaccine injection is administered 4 weeks or more before starting medication.

If already taking: Consider delaying first vaccine injection 12 weeks or more after the last Lemtrada or Mavenclad dose (optimal timing 24 weeks or more). If possible, resume Lemtrada or Mavenclad 4 weeks or more following the second vaccine injection. Vaccine response may be attenuated.

Ocrevus (ocrelizumab), Rituxan (rituximab)

If starting: Time dosing so that the second vaccine injection is administered 4 weeks or more before starting medication.

If already taking: Consider delaying first vaccine injection 12 weeks after the last treatment dose. If possible, resume treatment 4 weeks or more following the second vaccine injection. Vaccine response may be attenuated.

Kesimpta (ofatumumab)
If starting: Time dosing so that the second vaccine injection is administered 4 weeks or more before starting medication.

If already taking: Consider delaying first vaccine injection 4 weeks or more after the last Kesimpta injection. If possible, resume Kesimpta 4 weeks or more following the second vaccine injection. Vaccine response may be attenuated.

Consider getting the vaccine 3-5 days after the last dose of steroids.
High-dose steroids

Other immunotherapies commonly used to treat neurologic disease

If starting: Time dosing so that the second vaccine injection is administered 2-4 weeks or more before starting medication.

If already taking: No adjustments needed. Continue as prescribed. Vaccine response may be attenuated.

Uplizna (inebilizumab)

If starting: Time dosing so that the second vaccine injection is administered 2-4 weeks or more before starting medication.

If already taking: Consider delaying first vaccine injection 12 weeks after the last treatment dose. If possible, resume treatment 4 weeks or more following the second vaccine injection. Vaccine response may be attenuated.

\footnotetext{
a Based on recommendations from the National Multiple Sclerosis Society. ${ }^{\mathrm{e}, \mathrm{e} 8 \mathrm{e}, \mathrm{e} 22, \mathrm{e} 25}$
}

autoimmune neurologic disease. Methotrexate acts by inhibiting lymphocyte activation and results in a decreased response to pneumococcal vaccine. ${ }^{\text {e26 }}$ Similarly, azathioprine, mycophenolate mofetil, and systemic corticosteroids generally have been associated with decreased immunologic response to vaccines. ${ }^{\text {e27 }}$ The anti-interleukin-6 monoclonal antibody tocilizumab has thus far not been shown to attenuate humoral responses to vaccination, at least after short durations of therapy. ${ }^{\text {e28-e30 }}$ However, the possibility of decreased vaccine response must still be considered. The effect of eculizumab on vaccine response has not been extensively studied. When possible, it is generally prudent to complete vaccinations 2-4 weeks prior to initiating the above therapies, but treatment with these therapies does not preclude vaccination except for live-attenuated vaccines.

\section{Population-Specific Considerations}

Clearly, there is evidence that SARS-CoV-2 infection poses risk to patients with neurologic disease. Vaccination presents an opportunity to decrease transmission and reduce severity of infection within vulnerable populations. However, along with the optimal timing of vaccination, there are additional considerations for many groups, prompting national societies to offer statements in support of vaccine administration.

\section{Neuromuscular and}

\section{Neuroinflammatory Disorders}

The weakness and disability associated with neuromuscular and neuroinflammatory disorders can result in increased symptomatology with viral infection, though there is no clear 
evidence that infection is associated with increased risk of flare or disease progression. These patient populations are most likely to be treated with immunotherapies, which are discussed above in the context of SARS-CoV-2 infection and vaccination. Despite a paucity of data specifically evaluating the currently available COVID-19 vaccines in these groups, vaccination is expected to be safe. Both the American Academy of Neuromuscular and Electrodiagnostic Medicine and the National Multiple Sclerosis Society are in favor of vaccination for patients with neuromuscular disease and MS, regardless of immunosuppressive status. Although consensus guidelines from these groups discuss optimal timing of vaccination in relation to treatment with certain immunotherapies, it is important to note that vaccination should not necessarily be delayed if immediately available, as in some cases the risk of delaying even partial immunity may outweigh the benefit of waiting to achieve optimal vaccine response. $^{47,48, \mathrm{e} 25}$

For those patients treated with immunotherapies known or suspected to decrease vaccine response, patients should be counseled to remain vigilant about infection mitigation efforts even after vaccination due to the possibility of absent or diminished immunity. Evidence-based guidance does not exist regarding COVID-19 risk and appropriate ongoing safety measures for vaccinated patients on immunocompromising therapies. These issues are becoming increasingly relevant and challenging as a greater share of the population becomes vaccinated, leading to lifting of state- and locally mandated safety measures and recommendations regarding the return to normal activities for the fully vaccinated. ${ }^{\mathrm{e} 1}$ Some providers may choose to measure postvaccination antibody levels against the SARS-CoV-2 spike protein to assess vaccine response and aid in counseling these patients, although the clinical significance of such testing with regard to COVID-19 risk remains uncertain. Further studies are needed regarding how best to evaluate postvaccination immunity in this patient population and whether additional measures (such as booster vaccines) may be useful.

\section{Dementia, Cerebrovascular Disease, and the Elderly}

The possibility of side effects from vaccination is a significant concern in the elderly population, given that it includes many individuals with potential vulnerability due to cognitive impairment or cerebrovascular disease. However, the risk of viral infection is also highest in this demographic and the $\mathrm{Alz}$ heimer's Association is recommending vaccination for elderly individuals and their caregivers. ${ }^{\text {e32 }}$ More research is required to determine whether individuals with neurodegenerative cognitive disease are at risk for accelerated decline after COVID-19. Vaccine administration for the majority of patients with stroke and cardiovascular disease is also supported by the American Heart Association, ${ }^{\text {e33 }}$ as infection with COVID-19 can exacerbate neurologic sequelae of prior strokes. There are rare case reports of increased risk of stroke in young individuals with COVID-19 without traditional vascular risk factors, ${ }^{\mathrm{e} 34}$ as well as reports of clotting in individuals with severe COVID-19. ${ }^{\text {e35 }}$ There is as yet no evidence to suggest that those with traditional risk factors are at an increased risk of stroke. As of this writing, $75 \%$ of the elderly population of the United States have received at least 1 vaccine dose and 55\% are fully vaccinated. Careful surveillance will be required to determine whether there are age-related vaccination risks, but in the absence of clear data indicating increased risk, the clear impetus is to vaccinate that portion of the population that has constituted $80 \%$ of US deaths due to COVID-19 to date.

\section{Epilepsy}

Although seizures are not a common presentation of COVID19 , infection can increase seizure frequency in those at increased risk and the Epilepsy Foundation recommends the vaccine for eligible patients as there does not appear to be worsening of epileptic seizures following vaccine administration. ${ }^{\text {e36 }}$ There has been no evidence of increased risk of seizures following vaccination in those with a history of epilepsy.

\section{Children and Pregnant Women}

Recently, the first mRNA vaccine was approved for administration in children over 12 years of age; however, this review focuses on the ramifications of COVID-19 and evidence regarding safety of vaccination in the adult population, as the risk-benefit ratio is likely different between the 2 groups. Data are also sparse, although emerging, regarding the vaccine's use in pregnant women. ${ }^{\text {e37 }}$ Although "no obvious safety signals" were seen, we await further evidence of safety and efficacy.

\section{Underrepresented Populations}

Underrepresented populations, including the Black, Latinx, and indigenous communities, also merit special consideration due to disproportionate risk of morbidity and mortality related to SARS-CoV-2 infection ${ }^{\text {e38-e41 }}$ and disparities in access to available vaccines, ${ }^{\text {e2-e44 }}$ although no data exist specifically regarding the interaction between COVID-19 and preexisting neurologic illness in these groups. An additional challenge is vaccine hesitancy related to relative mistrust of the medical community, which stems from a variety of historical events and experiences. ${ }^{\mathrm{e} 45, \mathrm{e} 46}$ Of course, it is important to note that vaccine hesitancy is not restricted to underrepresented populations and transcends age, sex, race, and socioeconomic class, although the historical experiences producing hesitancy are often unique to these groups. Given the challenges facing underrepresented and underserved groups, strategies to increase vaccine access and advocacy within these communities remain critical.

\section{Discussion}

Given the widespread effect of the COVID-19 pandemic on adults with neurologic disease, the risks and benefits of vaccination must be considered for each patient. Although 
limited, the currently available data report low rates of neurologic complications postvaccination, particularly when weighed against the severity of morbidity and mortality resulting from the infection in populations of people with neurologic illness. Special consideration relative to the timing of vaccination should be given to groups currently treated with immunotherapies. Patients treated with immunotherapies known or suspected to attenuate vaccine response must be counseled about the ongoing potential for SARS-CoV-2 infection, an issue of increasing relevance as state and local safety mandates are lifted. As neurology providers, it is our duty to seek evidence-based guidance for our patients and to tailor education for all patient demographics. Due to the rapid development of the pandemic and COVID-19 vaccination, the current evidence base is limited in regard to patients with neurologic disease. However, barring the rare circumstance of an absolute contraindication to available vaccine formulations, it is the American Academy of Neurology's formal position that eligible patients should be offered the COVID19 vaccine. $^{\text {e47 }}$

\section{Acknowledgment}

The following individuals are members of the Quality Committee of the American Academy of Neurology that read and formally approved this statement: Christine B. Baca, MD (University of Colorado); Sarah M. Benish, MD (University of Minnesota Physicians); Jeffrey R. Buchhalter, MD; Calli L. Cook, DNP, FNP-C (Emory Healthcare); Allen L. Gee, MD, PhD (Frontier Neurosciences); Ihtsham Haq, MD (University of Miami Miller School of Medicine); Lyell K. Jones, MD (The Mayo Clinic); Adam Kelly, MD (University of Rochester); Kevin Kessler, MD (University of Virginia Medical Center); Elisabeth B. Marsh, MD (Johns Hopkins University School of Medicine); Anup D. Patel, MD (Nationwide Children's Hospital); Michael Phipps, MD, MHS (University of Maryland School of Medicine); Sonja Potrebic, MD, PhD (Southern California Permanente Medical Group); Alexander D. Rae-Grant, MD (Cleveland Clinic); Jose G. Romano, MD (University of Miami Miller School of Medicine); Amy E. Sanders, MD (Ayer Neuroscience Institute); and Adam Webb, MD (Emory University School of Medicine).

\section{Study Funding}

The authors report no targeted funding.

\section{Disclosure}

The authors report no conflicts of interest related to this work. E.B. Marsh receives funding for her research from the American Heart Association and National Institute of Aging (NIA) at the NIH. M. Kornberg receives funding for his research from the National Institute of Neurologic Disorders and Stroke (NINDS), Doris Duke Charitable Foundation, Conrad N. Hilton Foundation, and Race to Erase MS. He has received consulting fees from Biogen Idec, Janssen
Pharmaceuticals (unrelated to vaccine development), and OptumRx. I. Haq has received funding for his research from the NINDS and NIA and has served on advisory boards for Boston Scientific and Medtronic. A.D. Patel serves as a volunteer vice-chair of the American Academy of Neurology (AAN) Quality Committee. He receives research support from the Pediatric Epilepsy Research Foundation and NIH. He serves on a scientific advisory board for Neurelis and Greenwich Biosciences and performs webinar development for Medscape. A. Nath is the Clinical Director of NINDS at NIH. L.K. Jones serves as the voluntary Chair of the AAN Quality Committee, on the AANI Board of Directors, and Mayo Clinic ACO Board of Directors. K. Kessler and B. Schierman report no disclosures relevant to the manuscript. Go to Neurology.org/N for full disclosures.

\section{Publication History}

Received by Neurology May 5, 2021. Accepted in final form July 19, 2021.

Appendix Authors

\begin{tabular}{|c|c|c|}
\hline Name & Location & Contribution \\
\hline $\begin{array}{l}\text { Elisabeth B. } \\
\text { Marsh, MD }\end{array}$ & $\begin{array}{l}\text { The Johns Hopkins School } \\
\text { of Medicine, Baltimore, } \\
\text { MD }\end{array}$ & $\begin{array}{l}\text { Drafting/revision of the } \\
\text { manuscript for content, } \\
\text { including medical writing for } \\
\text { content; study concept or } \\
\text { design; analysis or } \\
\text { interpretation of data }\end{array}$ \\
\hline $\begin{array}{l}\text { Michael } \\
\text { Kornberg, } \\
\text { MD, PhD }\end{array}$ & $\begin{array}{l}\text { The Johns Hopkins School } \\
\text { of Medicine, Baltimore, } \\
\text { MD }\end{array}$ & $\begin{array}{l}\text { Drafting/revision of the } \\
\text { manuscript for content, } \\
\text { including medical writing for } \\
\text { content }\end{array}$ \\
\hline $\begin{array}{l}\text { Kevin } \\
\text { Kessler, MD }\end{array}$ & $\begin{array}{l}\text { The University of Virginia } \\
\text { Medical Center, } \\
\text { Charlottesville }\end{array}$ & $\begin{array}{l}\text { Drafting/revision of the } \\
\text { manuscript for content, } \\
\text { including medical writing for } \\
\text { content }\end{array}$ \\
\hline $\begin{array}{l}\text { Ihtsham } \\
\text { Haq, MD }\end{array}$ & $\begin{array}{l}\text { The University of Miami } \\
\text { Miller School of Medicine, } \\
\text { FL }\end{array}$ & $\begin{array}{l}\text { Drafting/revision of the } \\
\text { manuscript for content, } \\
\text { including medical writing for } \\
\text { content }\end{array}$ \\
\hline $\begin{array}{l}\text { Anup D. } \\
\text { Patel, MD }\end{array}$ & $\begin{array}{l}\text { Nationwide Children's } \\
\text { Hospital, Columbus, } \mathrm{OH}\end{array}$ & $\begin{array}{l}\text { Drafting/revision of the } \\
\text { manuscript for content, } \\
\text { including medical writing for } \\
\text { content }\end{array}$ \\
\hline $\begin{array}{l}\text { Avindra } \\
\text { Nath, MD }\end{array}$ & $\begin{array}{l}\text { National Institutes of } \\
\text { Health, Bethesda, MD }\end{array}$ & $\begin{array}{l}\text { Drafting/revision of the } \\
\text { manuscript for content, } \\
\text { including medical writing for } \\
\text { content }\end{array}$ \\
\hline $\begin{array}{l}\text { Becky } \\
\text { Schierman, } \\
\text { MD }\end{array}$ & $\begin{array}{l}\text { The American Academy of } \\
\text { Neurology, Minneapolis, } \\
\text { MN }\end{array}$ & $\begin{array}{l}\text { Drafting/revision of the } \\
\text { manuscript for content, } \\
\text { including medical writing for } \\
\text { content }\end{array}$ \\
\hline $\begin{array}{l}\text { Lyell K. } \\
\text { Jones, MD }\end{array}$ & $\begin{array}{l}\text { The Mayo Clinic, } \\
\text { Rochester, MN }\end{array}$ & $\begin{array}{l}\text { Drafting/revision of the } \\
\text { manuscript for content, } \\
\text { including medical writing for } \\
\text { content; study concept or } \\
\text { design }\end{array}$ \\
\hline
\end{tabular}




\section{References}

1. Weekly operational update on COVID-19. World Health Organization. Accessed February 22, 2021. who.int/publications/m/item/weekly-operational-update-oncovid-19

2. Gooch CL, Pracht E, Borenstein AR. The burden of neurological disease in the United States: a summary report and call to action. Ann Neurol. 2017;81(4):479-484

3. Moderna COVID-19 vaccine EUA letter of authorization. FDA. Accessed February 22, 2021. fda.gov/media/144636/download

4. Pfizer-BioNTech COVID-19 vaccine. FDA. Accessed February 22, 2021. fda.gov/ emergency-preparedness-and-response/coronavirus-disease-2019-covid-19/pfizerbiontech-covid-19-vaccine

5. FDA issues emergency use authorization for third COVID-19 vaccine. FDA. Accessed April 20, 2021. fda.gov/news-events/press-announcements/fda-issues-emergencyuse-authorization-third-covid-19-vaccine

6. Miravalle AA, Schreiner T. Neurologic complications of vaccinations. Handb Clin Neurol. 2014;121:1549-1557.

7. Mao L, Jin H, Wang M, et al.. Neurologic manifestations of hospitalized patients with coronavirus disease 2019 in Wuhan, China. JAMA Neurol. 2020;77(6):683-690.

8. Ellul MA, Benjamin L, Singh B, et al.. Neurological associations of COVID-19. Lancet Neurol. 2020;19:767-783.

9. Khoo A, McLoughlin B, Cheema S, et al. Postinfectious brainstem encephalitis associated with SARS-CoV-2. J Neurol Neurosurg Psychiatry. 2020;91(9):1013-1014.

10. Helms J, Kremer S, Merdji H, et al.. Neurologic features in severe SARS-CoV-2 infection. N Engl J Med. 2020;382(23):2268-2270.

11. Solomon $\mathrm{IH}$, Normandin E, Bhattacharyya S, et al.. Neuropathological features of covid-19. N Engl J Med. 2020;383(10):989-992.

12. Meinhardt J, Radke J, Dittmayer C, et al.. Olfactory transmucosal SARS-CoV-2 invasion as a port of central nervous system entry in individuals with COVID-19. Nat Neurosci. 2021;24(2):168-175.

13. Hanley B, Naresh KN, Roufosse C, et al. Histopathological findings and viral tropism in UK patients with severe fatal COVID-19: a post-mortem study. Lancet Microbe. 2020;1(6):e245-e253.

14. Thakur KT, Miller EH, Glendinning MD, et al. COVID-19 neuropathology at Columbia University Irving Medical Center/New York Presbyterian Hospital. medRxiv. Epub 2021 Mar 20.

15. Lee M, Perl DP, Nair G, et al.. Microvascular injury in the brains of patients with covid19. N Engl J Med. 2021;384(5):481-483.

16. Keyhanian K, Umeton RP, Mohit B, Davoudi V, Hajighasemi F, Ghasemi M. SARSCoV-2 and nervous system: from pathogenesis to clinical manifestation. J Neuroimmunol. 2021;350:577436.

17. Eliezer M, Hamel A, Houdart E, et al.. Loss of smell in patients with COVID-19: MRI data reveal a transient edema of the olfactory clefts. Neurology. 2020;95(23): e3145-e3152.

18. Brann DH, Tsukahara T, Weinreb C, et al.. Non-neuronal expression of SARS-CoV-2 entry genes in the olfactory system suggests mechanisms underlying COVID-19associated anosmia. Sci Adv. 2020;6:eabc5801.

19. Spence JD, De Freitas GR, Pettigrew LC, et al.. Mechanisms of stroke in COVID-19. Cerebrovasc Dis. 2020;49(4):451-458.

20. Merkler AE, Parikh NS, Mir S, et al.. Risk of ischemic stroke in patients with coronavirus disease 2019 (COVID-19) vs patients with influenza. JAMA Neurol. 2020; 77(11):1366-1372.

21. Rábano-Suárez P, Bermejo-Guerrero L, Méndez-Guerrero A, et al.. Generalized myoclonus in COVID-19. Neurology. 2020;95(6):e767-e772.

22. Foucard C, San-Galli A, Tarrano C, Chaumont H, Lannuzel A, Roze E. Acute cerebellar ataxia and myoclonus with or without opsoclonus: a parainfectious syndrome associated with COVID-19. Eur J Neurol. Epub 2021 Jan 25.

23. Urrea-Mendoza E, Okafor K, Ravindran S, Absher J, Chaubal V, Revilla FJ. Opsoclonus-myoclonus-ataxia syndrome (OMAS) associated with SARS-CoV-2 infection: post-infectious neurological complication with benign prognosis. Tremor Other Hyperkinet Mov. 2021;11:7.

24. Carroll E, Neumann H, Aguero-Rosenfeld ME, et al.. Post-COVID-19 inflammatory syndrome manifesting as refractory status epilepticus. Epilepsia. 2020;61(10): e135-e139.

25. Casals J, Elizan TS, Yahr MD. Postencephalitic parkinsonism: a review. J Neural Transm. 1998;105(6-7):645-676.

26. Vilensky JA, Gilman S, McCall S. A historical analysis of the relationship between encephalitis lethargica and postencephalitic parkinsonism: a complex rather than a direct relationship. Mov Disord. 2010;25(9):1116-1123.

27. Valerio F, Whitehouse DP, Menon DK, Newcombe VF. The neurological sequelae of pandemics and epidemics. J Neurol. 2020:1-27.

28. Lam MH, Wing Y, Yu MW, et al.. Mental morbidities and chronic fatigue in severe acute respiratory syndrome survivors: long-term follow-up. Arch Intern Med. 2009; 169(22):2142-2147.

29. Mertz D, Kim TH, Johnstone J, et al.. Populations at risk for severe or complicated influenza illness: systematic review and meta-analysis. BMJ. 2013;347:f5061.

30. Shea KM, Edelsberg J, Weycker D, Farkouh RA, Strutton DR, Pelton SI. Rates of pneumococcal disease in adults with chronic medical conditions. Open Forum Infect Dis. 2014;1:ofu024.
31. Neumann B, Angstwurm K, Mergenthaler P, et al.. Myasthenic crisis demanding mechanical ventilation: a multicenter analysis of 250 cases. Neurology. 2020;94(3): e299-e313.

32. Louapre C, Collongues N, Stankoff B, et al.. Clinical characteristics and outcomes in patients with coronavirus disease 2019 and multiple sclerosis. JAMA Neurol. 2020; 77(9):1079-1088.

33. Sormani MP, De Rossi N, Schiavetti I, et al.. Disease modifying therapies and covid-19 severity in multiple sclerosis. Lancet. 2021;89:780-789.

34. Choi B, Choudhary MC, Regan J, et al. Persistence and evolution of SARS-CoV-2 in an immunocompromised host. N Engl J Med. 2020;383(23):2291-2293.

35. Hoyer C, Ebert A, Huttner HB, et al. Acute stroke in times of the COVID-19 pandemic: a multicenter study. Stroke. 2020;51(7):2224-2227.

36. Chung YH, Beiss V, Fiering SN, Steinmetz NF. COVID-19 vaccine frontrunners and their nanotechnology design. ACS Nano. 2020;14(10):12522-12537.

37. Pardi N, Hogan MJ, Porter FW, Weissman D. mRNA vaccines: a new era in vaccinology. Nat Rev Drug Discov. 2018;17(4):261.

38. Custers J, Kim D, Leyssen M, et al. Vaccines based on replication incompetent Ad26 viral vectors: standardized template with key considerations for a risk/benefit assessment. Vaccine. 2021;39:3081-3101.

39. Baden LR, El Sahly HM, Essink B, et al.. Efficacy and safety of the mRNA-1273 SARSCoV-2 vaccine. N Engl J Med. 2021;384(5):403-416.

40. Thrombosis with thrombocytopenia syndrome (also termed vaccine-induced thrombotic thrombocytopenia). Accessed April 26, 2021. hematology.org/covid19/vaccine-induced-immune-thrombotic-thrombocytopenia

41. See I, Su JR, Lale A, et al. US case reports of cerebral venous sinus thrombosis with thrombocytopenia after Ad26.COV2.S vaccination, March 2 to April 21, 2021. JAMA. 2021;325:2448-2456.

42. MacNeil JR, Su JR, Broder KR, et al. Updated recommendations from the advisory committee on immunization practices for use of the Janssen (Johnson \& Johnson) COVID-19 vaccine after reports of thrombosis with thrombocytopenia syndrome among vaccine recipients: United States, April 2021. Morb Mortal Weekly Rep. 2021 70(17):651.

43. Pottegård A, Lund LC, Karlstad Ø, et al.. Arterial events, venous thromboembolism, thrombocytopenia, and bleeding after vaccination with oxford-AstraZeneca ChAdOx1-S in Denmark and Norway: population based cohort study. BMJ. 2021:373: n1114.

44. VAERS: Vaccine Adverse Event Reporting System. vaers.hhs.gov

45. Waheed W, Carey ME, Tandan SR, Tandan R. Post covid-19 vaccine small fiber neuropathy. Muscle Nerve. 2021;64:E1-E2.

46. Munro KJ, Uus K, Almufarrij I, Chaudhuri N, Yioe V. Persistent self-reported changes in hearing and tinnitus in post-hospitalisation COVID-19 cases. Int J Audiol. 2020 59(12):889-890

47. COVID-19 vaccine guidance for people living with MS. National Multiple Sclerosis Society. Accessed April 22, 2021. nationalmssociety.org/coronavirus-covid-19information/multiple-sclerosis-and-coronavirus/covid-19-vaccine-guidance

48. Živković SA, Gruener G, Narayanaswami P, et al. Doctor: Should I get the COVID-19 vaccine? Infection and immunization in individuals with neuromuscular disorders. Muscle Nerve. 2021;63:294-303.

49. Achiron A, Dolev M, Menascu S, et al. COVID-19 vaccination in patients with multiple sclerosis: what we have learnt by February 2021. Mult Scler J. 2021;27: 864-870.

50. Haber P, Sejvar J, Mikaeloff Y, DeStefano F. Vaccines and Guillain-Barré syndrome. Drug Saf. 2009;32(4):309-323.

51. Schonberger LB, Bregman DJ, Sullivan-Bolyai JZ, et al.. Guillain-Barré syndrome following vaccination in the national influenza immunization program, United States, 1976-1977. Am J Epidemiol. 1979;110(2):105-123.

52. Greene SK, Rett MD, Vellozzi C, et al. Guillain-Barré syndrome, influenza vaccination, and antecedent respiratory and gastrointestinal infections: a case-centered analysis in the vaccine safety datalink, 2009-2011. PLoS One. 2013;8(6):e67185.

53. Haber P, DeStefano F, Angulo FJ, et al.. Guillain-Barré syndrome following influenza vaccination. JAMA. 2004;292(20):2478-2481.

54. Lasky T, Terracciano GJ, Magder L, et al.. The Guillain-Barré syndrome and the 1992-1993 and 1993-1994 influenza vaccines. N Engl J Med. 1998;339(25): 1797-1802.

55. Grave C, Boucheron P, Rudant J, et al.. Seasonal influenza vaccine and Guillain-Barré syndrome: a self-controlled case series study. Neurology. 2020;94(20):e2168-e2179.

56. Vellozzi C, Iqbal S, Broder K. Guillain-Barré syndrome, influenza, and influenza vaccination: the epidemiologic evidence. Clin Infect Dis. 2014;58(8):1149-1155.

57. Lehmann HC, Hartung H, Kieseier BC, Hughes RA. Guillain-Barré syndrome after exposure to influenza virus. Lancet Infect Dis. 2010;10(9):643-651.

58. Kuitwaard K, Bos-Eyssen ME, Blomkwist-Markens PH, Van Doorn PA. Recurrences, vaccinations and long-term symptoms in GBS and CIDP. J Peripher Nervous Syst. 2009; 14(4):310-315.

59. Baxter R, Lewis N, Bakshi N, Vellozzi C, Klein NP; CISA Network. Recurrent Guillain-Barré syndrome following vaccination. Clin Infect Dis. 2012;54(6):800-804.

60. Sejvar J. Neurological events following immunizations. In: Nath A, Berger J, eds. Clinical Neurovirology, 2nd ed. CRC Press; Taylor and Francis Group; 2021:351-363. References e1-e47 are available at: links.lww.com/WNL/B482 


\section{Neurology}

\section{COVID-19 and Vaccination in the Setting of Neurologic Disease: An Emerging Issue in Neurology}

Elisabeth B. Marsh, Michael Kornberg, Kevin Kessler, et al.

Neurology 2021;97;720-728 Published Online before print July 29, 2021

DOI 10.1212/WNL.0000000000012578

This information is current as of July 29, 2021

\section{Updated Information \&} Services

References

Subspecialty Collections

Permissions \& Licensing

Reprints including high resolution figures, can be found at: http://n.neurology.org/content/97/15/720.full

This article cites 49 articles, 8 of which you can access for free at: http://n.neurology.org/content/97/15/720.full\#ref-list-1

This article, along with others on similar topics, appears in the following collection(s):

All Clinical Neurology

http://n.neurology.org/cgi/collection/all_clinical_neurology COVID-19

http://n.neurology.org/cgi/collection/covid_19

Public health

http://n.neurology.org/cgi/collection/public_health

Information about reproducing this article in parts (figures,tables) or in its entirety can be found online at:

http://www.neurology.org/about/about_the_journal\#permissions

Information about ordering reprints can be found online:

http://n.neurology.org/subscribers/advertise

Neurology ${ }^{\circledR}$ is the official journal of the American Academy of Neurology. Published continuously since 1951, it is now a weekly with 48 issues per year. Copyright Copyright (C) 2021 The Author(s). Published by Wolters Kluwer Health, Inc. on behalf of the American Academy of Neurology.. All rights reserved. Print ISSN: 0028-3878. Online ISSN: 1526-632X.

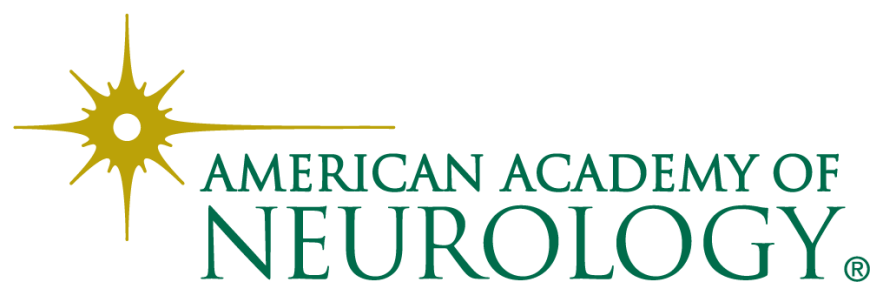

